九州大学学術情報リポジトリ

Kyushu University Institutional Repository

\title{
Experimental Investigation On The Spiral Pipe Performance For Particle-Laden Liquids
}

\section{Yanuar}

Department of Mechanical Engineering, Universitas Indonesia

\section{Ibadur rahman}

Department of Mechanical Engineering, Universitas Indonesia

A. S. Pamitran

Department of Mechanical Engineering, Universitas Indonesia

\section{Gunawan}

Department of Mechanical Engineering, Universitas Indonesia

他

https://doi.org/10.5109/4150509

出版情報：Evergreen. 7 (4)，pp.580-586，2020-12. 九州大学グリーンテクノロジー研究教育センター バージョン：

権利関係 : 


\title{
Experimental Investigation On The Spiral Pipe Performance For Particle-Laden Liquids
}

\author{
Yanuar $^{1, *}$, Ibadurrahman ${ }^{1}$, A. S. Pamitran ${ }^{1}$, Gunawan $^{1}$, Sealtial $\mathrm{Mau}^{2}$ \\ ${ }^{1}$ Department of Mechanical Engineering, Universitas Indonesia, Depok 16424, Indonesia \\ ${ }^{2}$ Doctoral Student of Department of Mechanical Engineering, Universitas Indonesia, Depok 16424, Indonesia
}

*Author to whom correspondence should be addressed:

E-mail: yanuar@eng.ui.ac.id

(Received November 4, 2020; Revised December 9, 2020; accepted December 16, 2020).

\begin{abstract}
Newtonian and non-Newtonian fluids are commonly transported with the piping system, but non-Newtonian fluids with particle-laden are more complicated to be transported due to various factors. A deposition is one of the problems that must be investigated due to affecting flow efficiency. The purpose of this study is to investigate the performance of 3-lobes spiral pipe in relationship with particles effect. The working fluid used had several variations of concentration weight (i.e. Cw 20\%, 30\% and 40\%). Test pipes used had $1550 \mathrm{~mm}$ of length which consisted of a spiral pipe with $P / D i=7$ and a circular pipe with an inner diameter of $25.4 \mathrm{~mm}$; both of the pipes were used to investigate the particles effect where the circular pipe for examining rheological of the working fluid. Slurry particles sized $1-5 \mu \mathrm{m}$ in this study was obtained from the mud eruption at Semau Island, Kupang-Indonesia. By comparing both working fluids, the critical velocity observed in the spiral pipe was not as high as observed in the circular pipe, and thus the spiral pipe is more efficient to be used in slurry transportation from mud eruption area.
\end{abstract}

Keywords: spiral pipe; pressure drop; solid particle; non-Newtonian; passive control

\section{Introduction and background}

The piping system is considered as the most effective medium of liquid transportation where it is widely used in industrial and engineering productivity and used to transport Newtonian and non-Newtonian fluids commonly ${ }^{1}$.

The flow of non-Newtonian fluid is more complicated than the Newtonian in regards to their flow in a pipe ${ }^{2}$. Various studies using non-Newtonian fluid have been attempted to reach a more efficient flow in order to reduce its energy consumption. Matoušek et al. ${ }^{3)}$ argued that each piping system designed for slurry (non-Newtonian fluid) must consider flow performance; he assumed that understanding the permanent contact between the particles and the wall is more important than the sporadic contact (collision) between the particles.

Two methods can be applied to obtain drag reduction, which directly relates to energy consumption reduction: active and passive control methods ${ }^{4}$. The active control method adds substances or additives through the working fluid ${ }^{5,6)}$, while the passive control method tries to reduce drag by forming or reshaping a channel geometry or structure to obtain more effective flow ${ }^{7,8)}$.

In the passive-control method, the working fluid determines the choice of appropriate pipe geometry to be used $^{7}$. Several solutions with various pipe cross-sections can be chosen for this problem, such as rectangular pipes $^{10)}$, pentagon spiral pipes ${ }^{11)}$, and spiral pipes with three or four-lobed variations ${ }^{12)}$.

The spiral pipe can be chosen as an alternative to prevent deposition, which often occurs in circular pipes which is the standard pipe used in the common piping system. Spiral pipe is an excellent alternative for more efficient-energy application and still environmentally friendly to be applied in the industry ${ }^{13}$. Yanuar et al. ${ }^{14)}$ revealed the influence of pipe wall geometry where they combined the active and passive control methods using surfactant in a spiral pipe. In their research of using spiral pipes to transport fluids, drag reduction is influenced not only by a mixture of drag-reducing agents but also by the wall of the pipe ${ }^{15}$. Their other study related the piping systems emphasised the conjunction of the impact on environmental losses and energy efficiency ${ }^{16)}$.

In Indonesia, mud eruption from a volcano often occurs, which has a detrimental impact when occurring near residential or agricultural areas. The mud eruption is a mixture of water and particles; its characteristics resemble a non-Newtonian fluid. This investigation on the spiral pipe performance for particle-laden liquids was carried out as a solution to tackle the mass non-Newtonian fluid transportation in Indonesia caused by the local rampant mud eruptions since several years ago.

Solid particles used for the working fluid mixtures were 
obtained from spout sources of mud eruption in Semau Island, East Nusa Tenggara-Indonesia, and thus the samples represent the real mud concentrate. The fluid mixture has a concentration weight $\left(C_{w}\right)$ of $20 \%, 30 \%$, and $40 \%$. The mixture used in the experiment can unravel the characteristic of the mud; the learned flow behaviour from the flow control will be a guide to solve the problems in the community related to mudflow. Whenever a detrimental of mud eruption occurs to a community, the mud can then be flowed efficiently to another place using this examined concept.

This research was conducted by using a 3-lobes spiral pipe as flow control (passive control). This paper is the first to research drag reduction, which analyses flow efficiency through particle behaviour (particle effect). A spiral pipe with a three-lobed cross-section and $\mathrm{P} / \mathrm{Di}=7$ was used because it has been proven efficient for twophase flow with high viscosity fluid. The objective of this study is to analyse the solid particles effect through the use of the spiral pipe.

\section{Method and experimental setup}

The experimental setup consists of the storage of slurry, slurry pump, circular and 3-lobes spiral pipes, pressure transducers with EMANT DAQ, a Laptop, a measurement cup and a weight scale. Pure water was used in the initial testing to find out leaks and to validate the measured pressure difference and mass flow rate. In order to find out the correct value of the pressure difference, two processes were examined: a careful measurement using manometer systems and then its comparison with the measurement using the pressure sensor. The mass flow rate was quantified with the conventional way using a measuring cup where it was weighed to find an accurate and more reliable value compared if using a digital flow meter, based on the authors' experience. Measurements value was collected for each working fluid concentration ( $C_{w}=20 \%, C_{w}=30 \%$ and $C_{w}=40 \%$ ) by varying the flow rate.

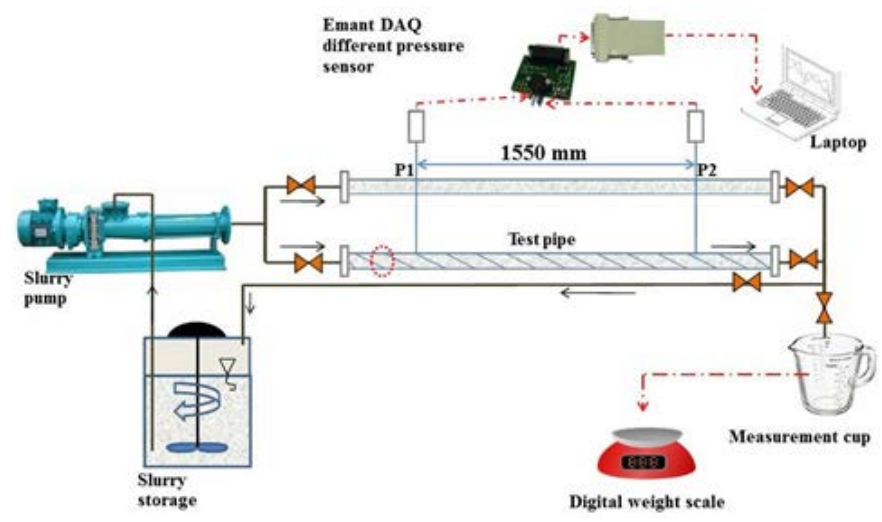

Fig. 1: Schematic diagram of the experimental setup.

In this study, the main focus is a spiral pipe for efficient flow and so the circular pipe as the standard pipe was also used as a comparison. Fig. 1 shows a schematic diagram of the flow loop to measure the velocity and pressure drop of the working fluids inside both pipes. The fluid was flowed to a test pipe using a slurry pump (gear pump) ${ }^{17}$. This type of pump was chosen due to the high viscosity of the transported fluid mixture ${ }^{18)}$. During the testing process, a rotating 1500-rpm mixer in the slurry storage tank protected it from being precipitated. Then, before reaching the main test pipe, it had to cross a pipe section with a length of $40 \mathrm{Dh}$ to achieve a fully developed flow. Both the spiral and circular test pipes have the same total length of 1550 mm; Table 1 describes their properties, and Fig. 2 depicts the geometry of the spiral pipe used. The circular pipe has a different diameter with the spiral pipe because the hydraulic diameter of both pipes must be in the same dimension in order to be compared for analysis.

Table 1. Test pipe dimension.

\begin{tabular}{|c|c|c|c|c|c|}
\hline Pipe & Di (mm) & Do (mm) & $\Delta \mathbf{D}(\mathbf{m m})$ & P (Pitch) & P/Di \\
\hline Circular & 25.4 & 25.4 & - & - & - \\
\hline Spiral & 37 & 47.6 & 5.3 & 259 & 7 \\
\hline
\end{tabular}

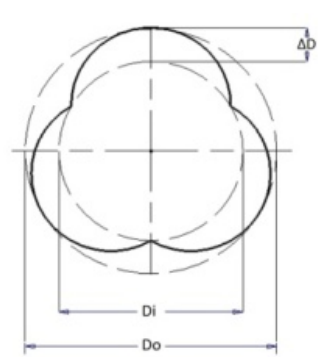

Front view

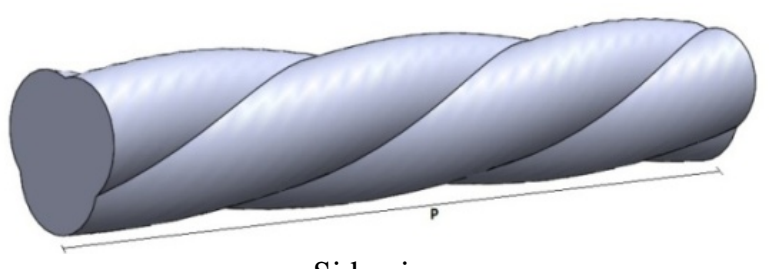

Side view

Fig. 2: Spiral pipe geometry.

On each of the pressure taps point, a sensor for pressure measurement was installed to collect pressure data. The sensor used (EMANT300) was a compact 24-bit data acquisition (DAQ) module developed for learning purposes ${ }^{19)}$; it can be calibrated to get measurement results with small errors and is exceptionally relevant for laboratory-scale research. The EMANT module has a working principle of recording different pressure $(\Delta \mathrm{p})$ values. The pressure values by the DAQ were validated by comparing it with carefully measured values using a manometer for certain flow variations. The different amount from the comparison was used as the added value to result of the DAQ. Only after this validation, the DAQ could be used to measure pressure in the experiment.

In this experiment, the room temperature was kept constant at $27^{\circ} \mathrm{C}$. The incoming flow was regulated by valve regulator ${ }^{20)}$, and the variations were set from lowest 
to maximum. In each time interval of the variations, the test fluid was collected on a container and then weighted with a digital scale with a high level of accuracy.

The investigated slurry was a mixture of the test ash particles obtained. For SEM measurement purpose, it was dried, and the ash particles were measured. Fig. 3 shows the size range of the SEM results, which is $1-5 \mu \mathrm{m}$. The dried slurry was then mixed with pure water with a concentration weight $C w$ of $20 \%, 30 \%$ and $40 \%$ using the following equation of

$$
C_{w}=\frac{m_{s}}{m_{w}+m_{s}} \times 100 \%
$$

where $m_{s}$ and $m_{w}$ are the solid particles mass and pure water mass, respectively. Before the experiment began, each concentration of the slurry was stirred with a mixer for an hour until it reached a homogeneous mixture.

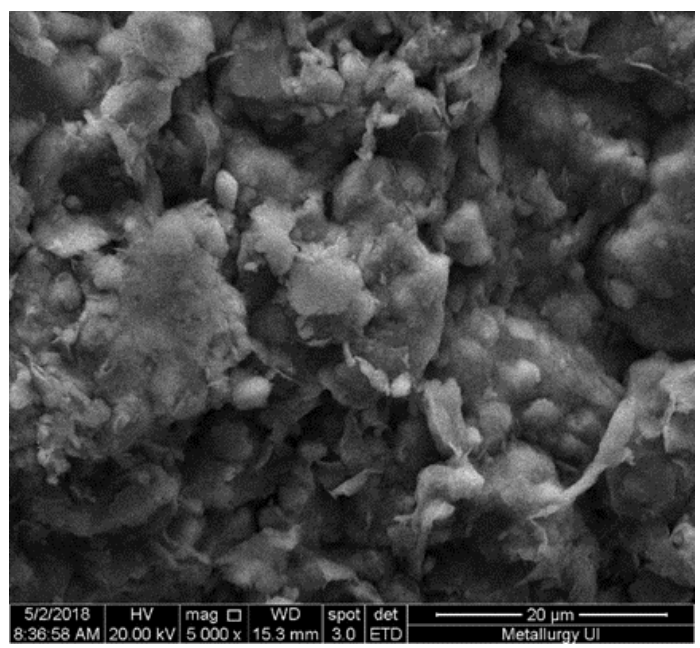

Fig. 3: SEM image of the slurry.

Rheological measurements were carried out at isothermal conditions with a constant temperature of $25^{0} \mathrm{C}^{21)}$. The rheological behaviour of non-Newtonian flow such as slurry can be known by the power-law model parameters, such as power-law index $(n)$ and consistency coefficient $(K)^{22)}$. These parameters can be obtained through scale plots between shear rates $\gamma=\dot{8} \bar{u} / D$ and shear stress $\tau=D \Delta P / 4 L_{P}{ }^{231}$. The slope and intersection value of the logarithmic graph indicate the values of $n$ and $K$, respectively. It should be noted that testing for the value of $n$ and $K$ uses data from circular pipes. The $n$ value indicates the working fluid as pseudoplastic fluid, and $K$ indicates zero shears of the working fluid ${ }^{24)}$. For a complex flow, such as a non-Newtonian fluid, the generalised Reynolds number $R e^{\prime}$ was used and defined as

$$
\operatorname{Re}^{\prime}=\frac{\rho \bar{u}^{2-n} D_{h}^{n}}{K 8^{n-1}}
$$

where $\rho$ is density, $\bar{u}$ is the mean velocity of the slurry, $D_{h}$ is the hydraulic diameter; the hydraulic diameter of the spiral pipe is calculated based on Yanuar et. al. ${ }^{25)}$.

The above equation of $R e^{\prime}$ is quoted from Benslimane et al. ${ }^{26)}$ and Kristiawan et al. ${ }^{27)}$ that simplify $R e^{\prime}$ calculation from Metzner et al. ${ }^{28)}$ to make them more relevant to the method of this investigation. The method used and the data obtained have a tendency towards the related references, so the use of the equations was adjusted accordingly.

The energy loss due to friction can be predicted by using the hydraulic gradient $\left(I_{\mathrm{m}}\right)$, which is defined as the head loss per unit length ${ }^{29)}$. The hydraulic gradient is an important parameter to evaluate the friction $\operatorname{loss}^{30}$ ) because it is the pressure gradient for a mixture expressed as the height of water per length of line ${ }^{31)}$ and defined as

$$
I_{m}=\frac{\Delta p}{\rho_{f} g L}
$$

where $\Delta p$ is a pressure drop, $\rho_{f}$ is the density of working fluid, $g$ is the gravity, and $L$ is the length of the test pipe.

The solid effect represented by $\left(I_{m}-I_{w}\right)$ was used to evaluate the additional friction loss due to the solid particles, where $I_{w}$ is the friction gradient for pure water at a flow rate equal to the slurry flow rate. Moreover, Durand equation is used to calculate the deposition critical velocity $V_{D C}{ }^{32)}$ as

$$
V_{D C}=F^{\prime}\left[2 g D_{h}(\mathrm{~s}-1)\right]^{1 / 2}
$$

where $F^{\prime}$ is an empirical function of diameter particle, and $s$ is relative density. $F$ ' depends on the drag coefficient of the particles settling in an equivalent fluid of density $\rho_{f}$ and viscosity $\mu_{f}^{33)}$. The correlation for $F$ ' is calculated as

$$
F^{\prime}=\exp \left[0.51-0.0073 C_{D}-12.5\left(K_{1}-0.14\right)^{2}\right.
$$

where $C_{D}$ is drag coefficient and $K_{1}$ is a factor that contains the viscosity and density of the water ${ }^{34)}$.

\section{Results and Discussion}

The non-Newtonian working fluid used in this study is a slurry from mud eruption. Before testing the working fluid, validation of the test equipment was carried out to ensure readiness. This initial testing was performed out using pure water, and mathematical equations were used to calculate the test data. Friction factors were calculated using the Hagen-Poiseuille equation for laminar flow ( $f=64 / R e$ ) and the Blasius equation for turbulent flow $\left(f=0.3164 R e^{-0.25}\right)$. For a Newtonian fluid, the Reynolds number of $R e=\rho \bar{u} D / \mu$ was used, and viscosity was not affected by the shear rate in the Newtonian fluid calculations. Eventually, the working fluid gradually flowed through the test pipe. 
Fig. 4 represents the data from the slurry test with $C_{w}$ variations (20\%, 30\% and 40\%). From the graphs, the higher mixture concentration produced a more significant pressure drop. This behaviour is similar to the increase in pressure drop when the flow rate increases.

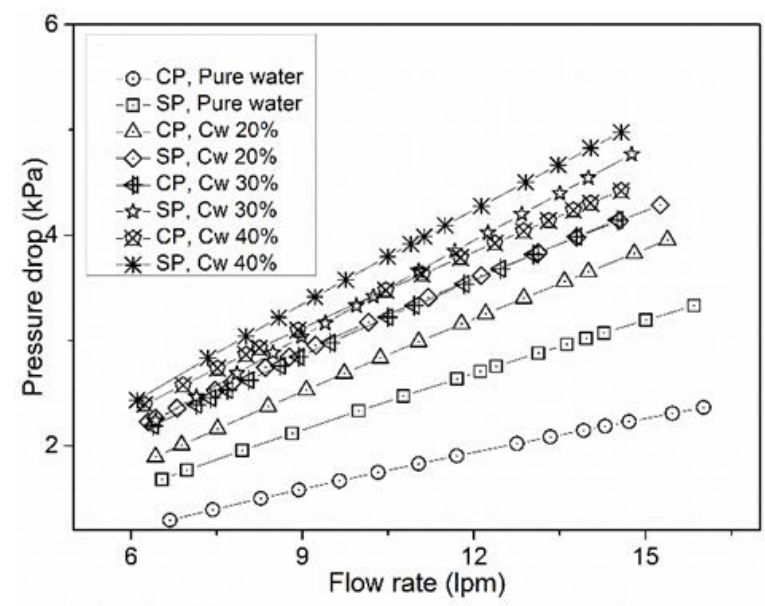

Fig. 4: Pressure drop and flow rate of the working fluids.

Fig. 5 compares shear stress and apparent viscosity in two $y$-axes, and shear rate in the $\mathrm{x}$-axis. The graph shows an increase in the shear rate, which resulted in an increase in shear stress and a decrease in apparent viscosity. It can be seen that the higher the concentration value of the fluid mixture, the higher the apparent viscosity resulted. The flow line of the plotted calculation data shows the trend of pseudoplastic flow behaviour, where the higher the shear rate, the apparent viscosity value drops. This behaviour is supported by the power law index of $n$ value obtained.

The calculation of $n$ and $K$ used the data of the circular pipes test and is presented in Table 2. The increase in the working fluid concentration resulted in a decrease of $n$, and the rising of $K$. The $n$ indicates the working fluid as pseudoplastic fluid, and $K$ indicates zero shears of the working fluid. This behaviour of pseudoplastic fluid flow results in a decrease of both the viscosity and the shear rate.

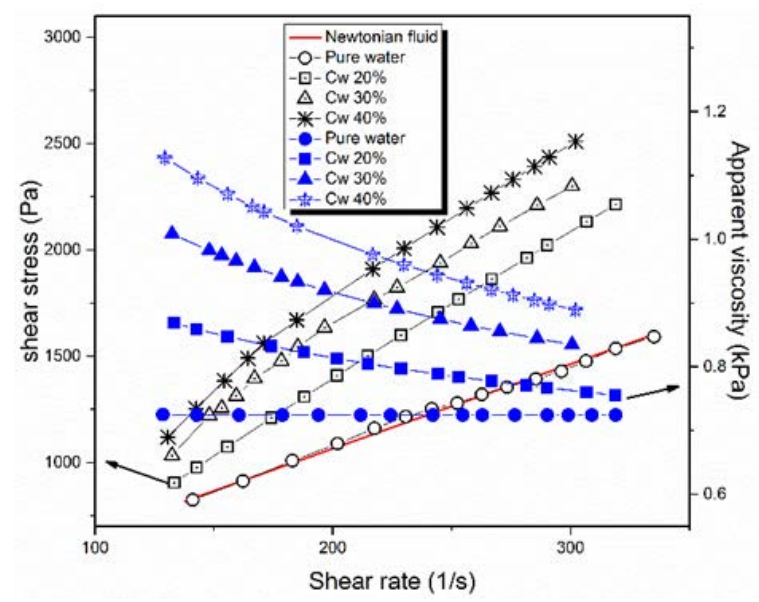

Fig. 5: Shear stress and apparent viscosity of the working fluid.
Table 2. Parameter power law from the circular pipes test

\begin{tabular}{|c|c|c|c|}
\hline \multirow{2}{*}{ parameter } & \multicolumn{3}{|c|}{ Working fluids } \\
\cline { 2 - 4 } & $C_{w}=20 \%$ & $C_{w}=30 \%$ & $C_{w}=40 \%$ \\
\hline$n$ & 0.99 & 0.92 & 0.81 \\
\hline$K$ & 6.1 & 12 & 20 \\
\hline
\end{tabular}

Fig. 6 presents a comparison of the hydraulic gradient of the generalised Reynolds number on a circular pipe and spiral pipe. At low Re', the hydraulic gradient value decreased sharply until $\mathrm{Re}^{\prime}=1 \times 10^{4}$, especially for the circular pipes. Then, the growth occurred when the fluid flow enters the turbulent zone. The variation of the mixture concentration generated varying hydraulic gradient for both types of pipe, each with their trend. The fluids differed in critical velocity magnitude since the concentration differences influenced them in the flow.

Particle-laden fluid experiences different velocities between particles and fluids at the initial velocity. The flow velocity soars until the particles are dragged or pushed in the direction of the flow; the initial velocity when the particles start to move is called the critical velocity. On the hydraulic gradient line, the critical velocity value can be found ${ }^{35)}$. The critical velocity is 0.46 $\mathrm{m} / \mathrm{s}, 0.79 \mathrm{~m} / \mathrm{s}$, and $1.02 \mathrm{~m} / \mathrm{s}$ for $C_{w}=20 \%, C_{w}=30 \%$, and $C_{w}=40 \%$, respectively.

The starting point of the hydraulic gradient growth indicated that higher velocity is needed to flow the solid particles by the threshold magnitude. The fluid in the circular pipe needed a higher threshold magnitude to flow the solid particles compared to the fluid in the spiral pipe even though they have the same mixture concentration. The high-velocity magnitude needed by the circular pipe is caused by relatively high energy that is required to move the particles which settled at the bottom of the pipe.

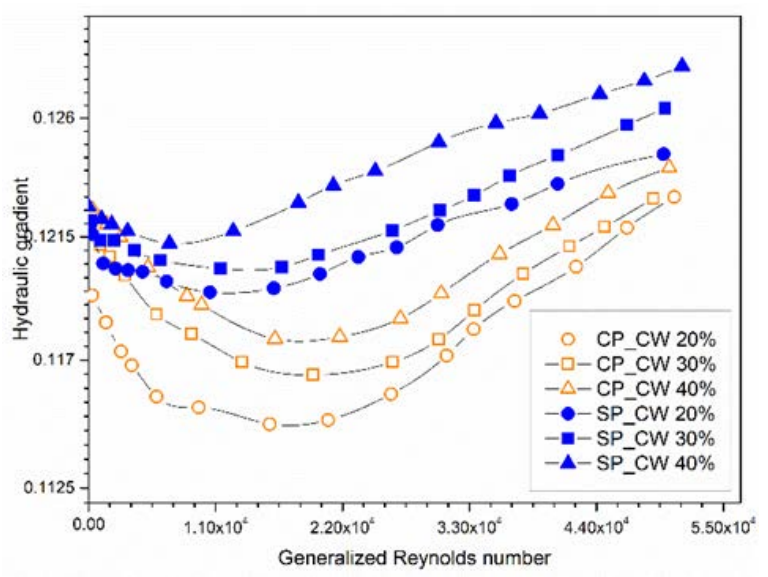

Fig. 6: Comparison of hydraulic gradients and generalised Reynolds numbers.

Fig. 7 describes the effect of solid particles $\left(I_{m}-I_{w}\right)$ in the

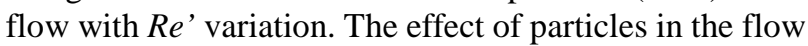
shows the degree of homogeneity of the working fluid, 
where the decreasing effect of the particles describes the better the homogeneity level.

The effect of solid particles in the case of the circular pipe grew with a more dense concentration of the mixture and grew less with the growth of Re'. This effect flattened for spiral pipes at $\mathrm{Re}^{\prime}=3 \times 10^{3}$, but shrunk for circular pipes at $\mathrm{Re}^{\prime}=3 \times 10^{4}$ and continued to shrink. The flattening effect of the spiral pipe indicates that there had been a homogeneous flow, and therefore it can be assumed that the particle interaction was more intense in the spiral pipe due to the swirl-flow pattern caused by its geometry. However, in the case of the circular pipe, there had not been a homogeneous flow described by the shrinking effect, which can be indicated that homogeneity in each mixture component was still happening.

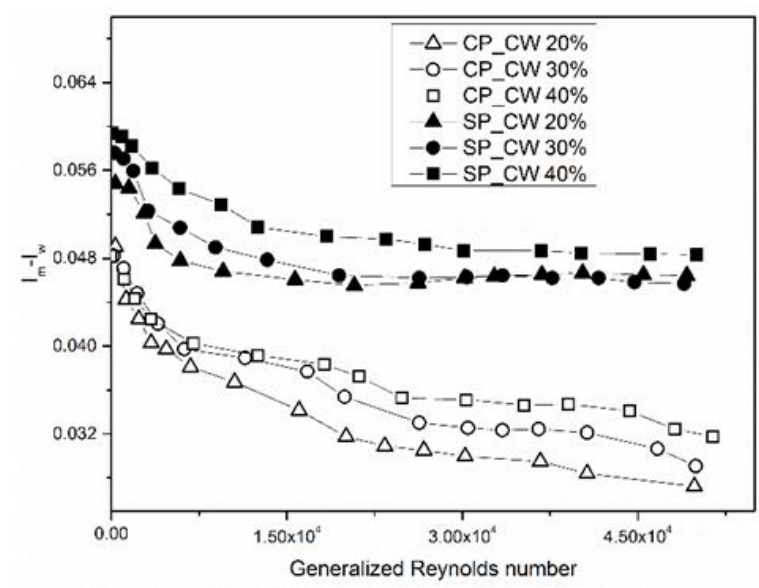

Fig. 7: Comparison of particle effects and generalised Reynolds numbers.

\section{Conclusions}

In order to investigate the performance of 3-lobes spiral pipe in relationship with particles effect of slurry from mud eruption, pressure drop and energy losses were measured and calculated. By the rheological model, the working fluid is known as the pseudoplastic with $n$ is less than 1. The effect of $R e$ ' and geometry pipes was presented; the critical velocity in circular and spiral pipes differed in value. Spiral pipe created less critical velocity than the circular pipe in order to move the solid particles in the fluid. The solid particle effect dropped sharply at low $R e^{\prime}$ and tended to be constant at specific $R e^{\prime}$ range. At the highest examined $R e^{\prime}$, the solid particles effect in the circular pipe still tended to fall, whereas in the spiral pipe this effect was flattened; the swirl shape of the pipe influenced this effect.

This research has provided information regarding the characteristics of two-phase flow that can be used to solve the transportation problem of mud eruption with the piping system. Research related to this field is still in progress using numerical simulations to determine the flow of particles dragged when it flows through a spiral pipe.

\section{Acknowledgements}

This research is sponsored by Penelitian Dasar (PD) Grant, No. NKB-1792/UN2.R3.1/HKP.05.00/2019 and NKB-2670/UN2.RST/HKP.05.00/2020 of Technology and Higher Education Ministry, Indonesia

\section{Nomenclature}

$\begin{array}{ll}C_{w} & \text { concentration weight (\%) } \\ D_{h} & \text { diameter hydraulic (m) } \\ f & \text { friction factor (-) } \\ F, & \text { the empirical function of diameter particle (-) } \\ g & \text { gravity ( } \mathrm{m} \mathrm{s}^{-2} \text { ) } \\ I_{w} & \text { friction gradient for pure water (-) } \\ I_{\mathrm{m}} & \text { hydraulic gradient (-) } \\ K & \text { consistency coefficient (-) } \\ L & \text { length of the test pipe (m) } \\ m_{S} & \text { solid particle mass (kg) } \\ m_{w} & \text { pure water mass (kg) } \\ n & \text { power-law index (-) } \\ R e & \text { Reynold number (-) } \\ R e^{\prime} & \text { generalised Reynold number (-) } \\ s & \text { relative density (-) } \\ V_{D C} & \text { critical velocity (m s-1) } \\ \Delta p & \text { pressure drop (Pa) }\end{array}$

Greek symbols

$\begin{array}{ll}\rho & \text { density }\left(\mathrm{kg} \mathrm{m}^{-3}\right) \\ \rho_{f} & \text { density of working fluid }\left(\mathrm{kg} \mathrm{m}^{-3}\right) \\ \mu_{f} & \text { viscosity of working fluid }\left(\mathrm{kg} \mathrm{m}^{-1} \mathrm{~s}^{-1}\right) \\ \bar{u} & \text { mean velocity }\left(\mathrm{m} \mathrm{s}^{-1}\right) \\ \dot{\gamma} & \text { shear rate }\left(\mathrm{s}^{-1}\right) \\ \tau & \text { shear stress }(\mathrm{Pa})\end{array}$

\section{References}

1) J. F. Steffe, "Rheological Methods in Food Process Engineering (Second Edition)." Freeman Press, 1992.

2) B. Deka, R. Sharma, A. Mandal, and V. Mahto, "Synthesis and Evaluation of Oleic Acid Based Polymeric Additive as Pour Point Depressant to Improve Flow Properties of Indian Waxy Crude Oil.” J. Petrol Sci. Eng.. 170 105-111 (2018).

3) V. Matoušek, "Research Developments in Pipeline Transport of Settling Slurries.” Powder Technology, 156 (1) 43-51 (2005).

4) A. M. Halawa, B. Elhadidi, and S. Yoshida, "Aerodynamic Performance Enhancement Using Active Flow Control on DU96-W-180 Wind Turbine Airfoil". Evergreen, 5 (1) 16-24 (2018). doi:10.5109/1929723

5) M. Gad-el-Hak, A. Pollard, and J.-P. Bonnet, "Flow 
Control: Fundamentals and Practices.” Springer Science \& Business Media, 2003.

6) J. A. Salami, C. Hu, and K. Hanada, "A Study on Smoothed Particle Hydrodynamics for Liquid Metal Flow Simulation.” Evergreen, 6 (3) 190-199 (2019). doi:10.5109/2349294.

7) A. S. Pamitran, S. Novianto, and S. A. Santoso, "Intermittent Flow Pattern on Two Phase Flow Boiling with Horizontal Microchannel.” Evergreen, 7 (1) 150-154 (2020). doi:10.5109/2740972.

8) J. Ganeshalingam, "Swirl-Induction for Improved Solid-Liquid Flow in Pipes.” University of Nottingham, 2002.

9) K. Watanabe, T. Maeda, T. Iwata, and H. Kato, "Flow in a Spiral Tube: 1st Report, Velocity Distribution and Pressure Drop.” JSME, 27 (228) 1105-1111 (1984).

10) S. Mau, and Yanuar, "Effect of Calcium Carbonate Solution on Drag Reduction in a Pentagon Spiral Pipe.” Akademia Baru, 1 41-48 (2018).

11) P. Selvaraj, J. Sarangan, and S. Suresh, "Experimental Investigation on Heat Transfer and Friction Factor Characteristics of a Water and Ethylene Glycol Mixture Flow of Internally Grooved Tubes.” Int. J. Chem. Res., 3 (1) 33-40 (2011).

12) C. Ariyaratne, "Design and optimisation of swirl pipes and transition geometries for slurry transport" University of Nottingham, 2005.

13) Yanuar, Gunawan, and M. Baqi, "Characteristics of Drag Reduction by Guar Gum in Spiral Pipes.” Jurnal Teknologi, $58 \quad$ (2) 95-99 (2012). doi:10.11113/jt.v58.1556.

14) Yanuar, Gunawan, and D. Sapjah, "Characteristics of Silica Slurry Flow in a Spiral Pipe.” IJTECH, 6 (6) (2015). doi:10.14716/ijtech.v6i6.1852.

15) Yanuar, G. G. Utomo, F. A. Rayhan, M. Akbar, and A. S. Pamitran, "Experimental Investigations of Ice Slurry Flow Based on Monoethylene Glycol at High Ice Fractions" E3S Web of Conferences, EDP Sciences, 2018.

16) P. Senapati, B. Mishra, and A. Parida, “Analysis of Friction Mechanism and Homogeneity of Suspended Load for High Concentration Fly Ash \& Bottom Ash Mixture Slurry Using Rheological and Pipeline Experimental Data.” Powder Technology, 250 154163 (2013).

17) K. R. Mrinal, Md. Hamid Siddique, and Abdus Samad, "Performance prediction of a centrifugal pump delivering non-Newtonian slurry." Particulate Sci. and Tech. $36 \quad$ (1) 38-45 (2018). doi.org/10.1080/02726351.2010.503264.

18) J. Ko, N. Takata, K. Thu, and T. Miyazaki, "Dynamic Modeling and Validation of a Carbon Dioxide Heat Pump System.” Evergreen, 7 (2) 172-194 (2020). doi:10.5109/4055215.

19) “Temperature Control with EMANT300,” Emant Pte Ltd. https://www.emant.com/ (accessed September 16, 2019)
20) D. Supramono, E. H. Lana, Setiadi, and M. Nasikin, "Effect of Carrier Gas Flow Rata on Bio-Oil Yield and Composition in Corn Cobs and Polypropylene Plastic Slow Co-Pyrolysis.” Evergreen, 6 (2) 149-156 (2019). hdl.handle.net/2324/2320999

21) A. A. Collyer, "Techniques in Rheological Measurement,” Chapman \& Hall, 1993. doi:10.1007/978-94-011-2114-9.

22) T. Cochrane, K. Walters, and M. F. Webster, "On Newtonian and non-Newtonian flow in complex geometries," Phil. Trans. of the Royal. Sc. of Lon. Ser. A, Math. and Phi. Sci., 301 163-181 (1981). doi:10.1098/rsta.1981.0103

23) R. P. Chhabra, and J. F. Richardson, "Non-Newtonian flow in the process industries: fundamentals and engineering applications,” Butterworth-Heinemann, 1999.

24) D. Boger, "Demonstration of upper and lower Newtonian fluid behaviour in a pseudoplastic fluid." Nature, 265 126-128 (1977). doi:10.1038/265126a0

25) Yanuar, K. T. Waskito, S. Mau, W. Wulandari, and S. P. Sari, "Helical Twisted Effect Of Spiral Pipe In Generating Swirl Flow For Coal Slurries Conveyance." 79 (7-3) 69-79 (2017). doi:10.11113/jt.v79.11899.

26) A. Benslimane, K. Bekkour, P. François, and H. Bechir, "Laminar and turbulent pipe flow of bentonite suspensions.” J. Pet. Sci. Eng., 139 85-93 (2016). doi:10.1016/j.petrol.2015.12.020.

27) B. Kristiawan, S. Kamal, and Yanuar, "ThermoHydraulic Characteristics of Anatase Titania Nanofluids Flowing Through a Circular Conduit.” $J$ Nanosci Nanotechnol, 16 (6) 6078-6085 (2016). doi:10.1166/jnn.2016.10902

28) K. Madlener, B. Frey, and H. K. Ciezki, "Generalized Reynold number for non-Newtonian fluids.” Progress in Propulsion Physics, 1 237-250 (2009). doi:10.1051/eucass/200901237

29) B. E. Abulnaga, "Slurry systems handbook," McGraw-Hill, New York, 2002.

30) D. F. Atwood, and S. M. Gorelick, "Hydraulic gradient control for groundwater contaminant removal,” J. of Hydrology, 76 (1-2) 85-106 (1985). doi:10.1016/0022-1694(85)90091-5.

31) C. Kim, M. Lee, and C. Han, "Hydraulic transport of sand-water mixtures in pipelines Part I. Experiment.” J Mech Sci Technol, 22 (12) 2534-2541 (2008). doi:10.1007/s12206-008-0811-0

32) R. Durand, E. Condolios, "Compte Rendu des Deuxièmes” Journées de l'Hydraulique, Société Hydrotechnique de France, Paris, 29-55 (1952).

33) R. Durand, "Basic relationships of the transportation of solids in pipes experimental research.” Proc. Minn. Int. Hyd. Conv., 89-103 (1953).

34) K.C. Wilson, "Deposition limit nomograms for particles of various densities in pipeline flow." Proc. Hydrotransport 6 Conf., BHRA, 1-12 (1979). 
35) A. K. Mehmet and G. Mustafa, "Critical Flow Velocity in Slurry Transporting Horizontal Pipelines.” J Hydraul Eng, 127 (9) 763-771 (2001). doi:10.1061/(ASCE)07339429(2001)127:9(763). 